\title{
A Theoretical Study of Market Performance under Price Limits and Circuit Breakers in Chinese Stock Market
}

\author{
Xinhong Hu \\ School of Economics and Management, Tsinghua University, Beijing, China \\ Email: huxh.14@sem.tsinghua.edu.cn
}

How to cite this paper: Hu, X.H. (2020) A Theoretical Study of Market Performance under Price Limits and Circuit Breakers in Chinese Stock Market. Theoretical Economics Letters, 10, 218-231. https://doi.org/10.4236/tel.2020.101014

Received: January 10, 2020

Accepted: February 24, 2020

Published: February 27, 2020

Copyright $(2020$ by author(s) and Scientific Research Publishing Inc. This work is licensed under the Creative Commons Attribution International License (CC BY 4.0).

http://creativecommons.org/licenses/by/4.0/

\begin{abstract}
The effectiveness of circuit breakers is widely discussed in previous studies, but few of them distinguish between price limits and market-wide circuit breakers. We develop a two-period Stackelberg game, testing the behavioral change of informed and uninformed investors under different circuit breakers. We find that informed investors become more conservative and trade in smaller sizes under circuit breakers, especially market-wide circuit breakers. But uninformed investors trade quite oppositely. This behavioral change makes stock price less informative, and dominated by investor sentiment. We also contribute the market crash in early January, 2016 to this behavioral change.
\end{abstract}

\section{Keywords}

Circuit Breakers, Price Limits, Information, Investors, Liquidity

\section{Introduction}

Circuit breakers refer to a trading suspension mechanism to control market fluctuation. They halt trades on the market level when price reaches a pre-determined breaking point. This mechanism was implemented firstly in the US after the market crash in 1987 and proved effective in many countries.

In September 2015, China Securities Regulatory Commission (CSRC) held a hearing conference for some policies, including bringing circuit breakers into the market, and this policy was approved in that hearing conference. The details for this policy were set up in December, and the benchmark of the circuit breaker was the CSI 300 index. If the CSI 300 index drops 5\% in one trading day, then trading will stop for 15 minutes when there is more than 15 minutes left for that trading day. After the 15-minute halt, the market will re-open and trades will 
continue. If the index keeps dropping for $7 \%$ after the break, the market will end up trading for the rest of the day.

The policy became valid at Jan $4^{\text {th }}, 2016$, the first trading day in 2016 after the New Year holiday. The 5\% and 7\% cordon were both reached at that day, and market paralyzed. The same situation happened three days after. And CSRC abolished this policy on Jan $8^{\text {th }}$, one day after the second 7-percent-cordon-reach day.

Circuit breakers are set as a market microstructure measurement in many countries, and there are many forms of them. Early studies discuss the effectiveness of circuit breakers (Lee et al., 1994 [1]; King et al., 1991 for the NYSE market [2], and Kryzanowski, 1979 for the Toronto Stock Exchange market [3]). These mechanisms were set up to cool down the market when there is a large change in price, making people digest information before trading. However, side effect is combined with circuit breakers, and the most famous one is called "magnet effect". Magnet effect was first raised in 1994. It supposes that under circuit breakers, price may become more volatile when it is approaching the threshold of circuit breaker, making circuit breakers more easily triggered.

However, magnet effect doesn't explain the severe drop in Chinese market, as we already have another market microstructure measurement in market: price limits. Like circuit breakers, price limits are another measurement preventing market from large move. This measurement exists mostly in emerging markets, where markets are regarded as more volatile and more irrational.

Price limit rules also have its side effects. Such as magnet effect (Subrahmanyam, 1994 [4]; Ackert et al., 2001 [5]); volatility spillover effect; delayed price discovery effect; trading interference effect (Fama, 1989 [6]; Kim and Rhee, 1997 [7]; Chen et al., 2005 [8]). These effects show that price limits may not work in the way we want. However, in most previous studies, we did not distinguish between price limits and circuit breakers, and people treat them as the same. This means if we introduce circuit breakers into a market where price limits already exist, circuit breakers should have no impact based on these studies.

There are some empirical papers testing effect under broadening of price limits (Thailand from $10 \%$ to $30 \%$; Korea from $6 \%$ to $15 \%$ ), and some studies about the switch between price limits to circuit breakers (Egypt from $5 \%$ price limit to $20 \%$ circuit breaker). But most of them still test the side effect of price limits, rather than studying the difference between price limits and circuit breakers.

In this paper, we try to study the difference between circuit breakers and price limits in another perspective: the liquidity perspective. The hypothesis of this paper is inspired by Subrahmanyam (1997) [9] and Heish (2007) [10]. They discussed the strategies of informed traders under circuit breakers and price limits, and discussed the price impact of different orders in an information perspective. Both of them conclude that under circuit breakers (price limits), informed traders may decrease the amount of their orders in order to make the market not stop. However, because there are some differences between circuit breakers and price limits, the suspension of trading can have different consequences. 
We present a two-period Stackelberg game based on Heish (2007) [10], by adding market-wide circuit breakers and price limits into the model. In our model, under market-wide circuit breakers, nobody can complete their trade if the market stops. However, if trading is suspended under price limits, there's still a probability of completing orders, which will lead to different trading strategies among investors.

Due to the difference of strategies, informed traders may be more conservative under market-wide circuit breakers than price limits, because large orders may cause the market stop and makes no profit in the second period. The conservatism makes stock prices less informative. However, uninformed investors become more aggressive and realize their liquidity need in the first period, because the fear of liquidity loss in period 2. Prices may become more volatile because it is less informative and dominated by investor sentiments. Individual investors tend to rush out of the market because their irrational illiquidity fear, and this effect will be stronger under market-wide circuit breakers.

Our paper broadens papers linking price limits and circuit breakers. And we focus on the mechanism difference between the two microstructure measurements. The market crash in China during Jan $4^{\text {th }}-7^{\text {th }} 2016$ may due to lots of reasons. For examples, Liquidity constraint may discourage people from trading (Heish 2007 [10]; Brunnermiere 2008 [11]) and rush out of the market; irrational behavior of investors (Kim and Rhee 1997 [7]; Chen et al. 2005 [8]) may also cause the crash; moreover, the market run can be attributed to the new policy adaptation or even new-year effect. The implementation of market-wide circuit breakers provides us a great chance to study the effectiveness of circuit breakers in a market microstructure perspective.

The paper is presented in the following order. In section I, we present the introduction of this paper. A Stackelberg sequential move model is presented in section II, in which we discuss the differences between circuit breakers and price limits and their impact on different investors. Section III is the conclusion.

\section{Theoretical Analysis}

\subsection{Baseline Model}

We present a two-period model based on Subrahmanyam (1997) [9] and Easley and O'Hara (1987) [12] to explain what will happen when we add circuit breaker into a market with price limit.

There are two types of investors in a market with only one stock: informed investor and uninformed investor. Suppose the fraction of informed investors in the market is $\mu$. Informed investors may receive information of the true value of stock in each period. Suppose in each period, the probability of receiving information is $\alpha$ for informed investors. Because of the downwardness of circuit breakers and the symmetry of model, we focus on the selling side and the downward trend of price. In our model, each investor can declare an order number per period, the order number can be $S_{1}$ or $S_{2}$, for simplicity, we de- 
fine $S_{2}=2 S_{1}$. There is also a market maker who set the price after two types of investors set their demands. After the price is set, the value of stock realizes, the value can be either $\bar{V}$ or $\underline{V}$. The ex-ante probability of $\underline{V}$ is $\delta>1 / 2$, i.e. in a downward market. The value of the stock is $V^{*}=\delta \underline{V}+(1-\delta) \bar{V}$ before both types of investor make their choices. After the period 1 trades, the probability turns into $\delta(S)$, making $V(S)=\delta(S) \underline{V}+(1-\delta(S)) \bar{V}$. Similarly, after period 2 trading, probability turns into $\delta\left(S, S^{\prime}\right)$, and $V\left(S, S^{\prime}\right)=\delta\left(S, S^{\prime}\right) \underline{V}+\left(1-\delta\left(S, S^{\prime}\right)\right) \bar{V}$. The sequential move of this two period model shows as Figure 1.

In our model, because of symmetry, we focus on informed investors who possess information of the underlined value of stock, which is $\underline{V}$, in each period. Suppose informed investors can short or long stocks arbitrarily, and the discount rate set as 1 . Based on their information and trading strategy $\left(S, S^{\prime}\right)$, the profit of informed investors is

$$
\Pi\left(S, S^{\prime}\right)=S(V(S)-\underline{V})+S^{\prime}\left(V\left(S, S^{\prime}\right)-\underline{V}\right)
$$

For uninformed investors, suppose they have a liquidity demand, the demand size is $S_{2}$ with probability $X_{2}$ and $S_{1}$ with probability $X_{1}$ at beginning of each period. We firstly hold the strategy of uninformed traders still, that is, they will satisfy their liquidity need in the beginning of period, and focus on the strategy of informed investors.

According to Heish (2007) [10], there exists two types of equilibrium in this game: separating equilibrium in which informed traders bids $S_{2}$ if they receive information of $\underline{V}$ or $S_{1}$ if they don't receive information; and pooling equilibrium in which informed trader bids either $S_{1}$ or $S_{2}$. We will derive the condition of the two equilibrium as Proposition 1, but we want to focus on the separating equilibrium.

\section{Proposition 1:}

In the two-period baseline model, the equilibrium exists based on the following conditions:

1) If

$$
\frac{S_{2}}{S_{1}} \geq \frac{1-\delta\left(S_{1}\right)}{1-\delta\left(S_{2}\right)+\delta\left(S_{1}, S_{2}\right)-\delta\left(S_{2}, S_{2}\right)}
$$

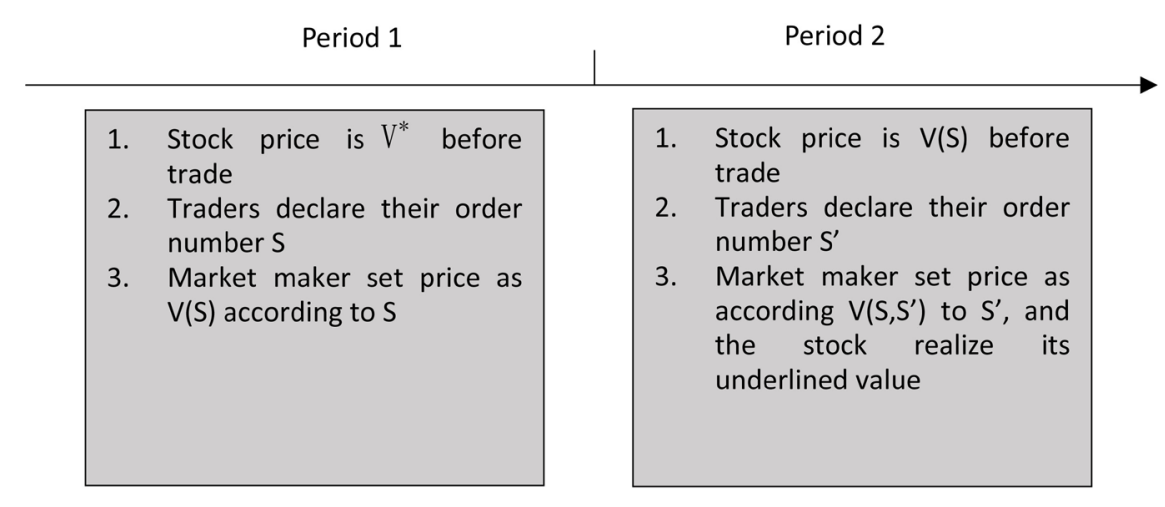

Figure 1. Sequential move of the model. 
There exists separating equilibrium in both periods.

2) If

$$
\frac{1-\delta}{1-\delta\left(S_{2}, S_{2}\right)} \leq \frac{S_{2}}{S_{1}} \leq \frac{1-\delta\left(S_{1}\right)}{1-\delta\left(S_{2}\right)+\delta\left(S_{1}, S_{2}\right)-\delta\left(S_{1}, S_{2}\right)}
$$

There exists a separating equilibrium in period 2 , and a pooling equilibrium in period 1.

3) If

$$
\frac{S_{2}}{S_{1}} \leq \frac{1-\delta}{1-\delta\left(S_{2}, S_{2}\right)}
$$

There exists pooling equilibrium in both periods.

\section{Proof: see Appendix.}

The intuition of these two equilibria is as follow. For informed investors, they do the profit and cost trade-off each period. If informed traders release their information to the market, they can receive higher profit in period 1. But the market will soon recognize them as informed traders, and set the price lower, making the profit margin smaller in period 2. In summary, releasing information only profit informed investors in the short term, but harm their long-term interests. According to this, informed investors tend to compare the profit and cost, and set for large size (separating equilibrium) if the profit is relatively large.

However, when we introduce circuit breakers into the market in section 2.2, we will find that informed investors will change their trading strategies, making the market condition changes as well.

\subsection{Introduction of Price Limits and Circuit Breakers}

We now introduce circuit breakers and price limits into this model base on the set up above.

For both circuit breakers, we introduce it as Subrahmanyam (1997) [9]. In the 1997 paper, circuit breaker triggers when the price dropped below the exogenous cordon. In other words, if the change of price $\Delta(S)=V^{*}-V(S)$ is greater than $C$, then the circuit breaker works. We do not distinguish the 5 or 7 percent drop in the Chinese policy here, and suppose all trading will be suspended until the true value of $V$ is realized, if the cordon of circuit breaker is reached. Once the market stops, nobody will complete their bids in the market, including both informed and uninformed traders. Which means investors will get zero profit if the circuit breaker is triggered. i.e. The profit will be $\Pi(S)=S(V(S)-\underline{V})$ if circuit breakers triggers in period 1.

As for price limits, the set up is similar to circuit breakers. When the change is greater than $C$, price limits triggers. The difference between price limit and circuit breaker is what happens after their cordon is reached. If circuit breaker triggers, the entire market stops until the true value is revealed, which it is not the case under price limit. If price limit works, the price will be set at $\underline{P}=V^{*}-C$. The market will not stop, but all trades should be traded at price $\underline{P}$ 
till the true value revealed. Moreover, because the price is stopped at some exogenous point, the demand and supply may not achieve the condition of an equilibrium. In this case, more people tend to sell the stock rather than buy it. So in order to solve this inequality, each investor has a probability of $\gamma$ of getting traded. For informed investors, they will complete their trades at probability $\gamma$ at price $\underline{P}$. i.e. The profit will be $\Pi^{\prime}\left(S, S^{\prime}\right)=S(V(S)-\underline{V})+r S^{\prime}(\underline{P}-\underline{V})$.

We first analyze the strategy of informed investors. Focusing on the separating equilibrium in the benchmark case, we can derive the strategies of informed investors as proposition 2.

\section{Proposition 2:}

Under separating equilibrium, when we introduce market-wide circuit breakers or price limits into the market:

1) If $\Delta\left(S_{1}\right)>C$, both circuit breakers will be triggered.

2) If $\Delta\left(S_{2}\right)<C$, market will never trigger any circuit breakers.

3) If $\Delta\left(S_{1}\right) \geq C \geq \Delta\left(S_{2}\right)$, market will trigger circuit breakers if investors declare large orders in period 1 . The strategy of informed investors can be determined by the following conditions:

3.1) Under market-wide circuit breakers, if

$$
\frac{S_{2}}{S_{1}} \geq \frac{1-\delta\left(S_{1}\right)}{\delta\left(S_{1}, S_{2}\right)-\delta\left(S_{2}\right)}
$$

Informed investors will set large orders in period 1, triggering the circuit breakers threshold and stops the market in period 2 . If

$$
\frac{1-\delta\left(S_{1}\right)}{1-\delta\left(S_{2}\right)+\delta\left(S_{1}, S_{2}\right)-\delta\left(S_{2}, S_{2}\right)} \leq \frac{S_{2}}{S_{1}}<\frac{1-\delta\left(S_{1}\right)}{\delta\left(S_{1}, S_{2}\right)-\delta\left(S_{2}\right)}
$$

Informed investors will declare small orders in period 1, making the market continue trading in period 2.

3.2) Under price limit rules, if

$$
\frac{S_{2}}{S_{1}} \geq \frac{1-\delta\left(S_{1}\right)}{\delta\left(S_{1}, S_{2}\right)-\delta\left(S_{2}\right)+\gamma\left(1-\delta\left(S_{2}, S_{2}\right)\right)}
$$

Informed investors will set large orders in period 1, triggering the price limit threshold, stopping part of trades in period 2. If

$$
\frac{1-\delta\left(S_{1}\right)}{\delta\left(S_{1}, S_{2}\right)-\delta\left(S_{2}\right)+1-\delta\left(S_{2}, S_{2}\right)} \leq \frac{S_{2}}{S_{1}}<\frac{1-\delta\left(S_{1}\right)}{\delta\left(S_{1}, S_{2}\right)-\delta\left(S_{2}\right)+\gamma\left(1-\delta\left(S_{2}, S_{2}\right)\right)}(8)
$$

Informed investors will declare small orders in period 1, making the market continue trading in period 2.

\section{Proof: see Appendix.}

Under separating equilibrium, investors tend to set large orders because trading in large amount will bring them more profits, even though profit for each stock is lower because the price for a large trade is lower than price for a small amount. 
However, this is not the case when we introduce price limits or circuit breakers into the model. When there is a circuit breaker in the market, if the informed trader trade in a large trade, the bid price must be lower, which means the change of price is larger. And it is more likely that the change of price is out of range, then the circuit breaker will be triggered and market will stops. Under price limits, this case also stands. If the informed traders insist to trade in large size, the change of price may be larger than $C$, which makes them achieve their orders at probability $\gamma$ at price $\underline{P}$.

If informed traders trade in the large amount, the price will drop below the cordon and the market will be stopped. This will make informed investors get zero profit in period 2. However, if they trade in small size, they can achieve profit of $S_{1}\left(V\left(S_{1}\right)-\underline{V}\right)$, lower than the profit of trading in large amount in the original case, but higher than zero.

The story of price limit is slightly different with market-wide circuit breakers. Suppose now $\Delta\left(S_{1}\right) \leq C \leq \Delta\left(S_{2}\right)$ holds, because part of trade can still be completed even when price limit triggers, we cannot direct conclude that informed traders will split their demand, and informed investors may still tend to trade in a big size.

By comparing conditions (6) and (8), we can derive

$$
\frac{1-\delta\left(S_{1}\right)}{\delta\left(S_{1}, S_{2}\right)-\delta\left(S_{2}\right)+\gamma\left(1-\delta\left(S_{2}, S_{2}\right)\right)}<\frac{1-\delta\left(S_{1}\right)}{\delta\left(S_{1}, S_{2}\right)-\delta\left(S_{2}\right)}
$$

If we have

$$
\frac{1-\delta\left(S_{1}\right)}{\delta\left(S_{1}, S_{2}\right)-\delta\left(S_{2}\right)+\gamma\left(1-\delta\left(S_{2}, S_{2}\right)\right)} \leq \frac{S_{2}}{S_{1}} \leq \frac{1-\delta\left(S_{1}\right)}{\delta\left(S_{1}, S_{2}\right)-\delta\left(S_{2}\right)}
$$

We can tell that under this circumstance, informed investors will split their orders under market-wide circuit breakers, but tend to concentrate their orders under price limits. This is because under market-wide circuit breakers, the entire market will stop if circuit breaker triggers, making no profit in period 2. However, investors are still expected to complete trade with probability $\gamma$ under price limits. Based on this difference, the fear of illiquidity will be smaller under price limits, making institutional investors more willing to release their information into the market under price limit rules, and large orders tend to be more informative.

This conclusion is consistent with Subrahmanyam (1994) [4] and Heish (2007) [10]. However, the two papers did not distinguish between market-wide circuit breakers and price limits. In our comparison, market is more fragile under market-wide circuit breakers. This is because informed investors tend to hide their information, and set for small orders in trading. As they become more conservative, there will be less information released into the market, and the market may be dominated by irrational behavior or investors' sentiment, making market more volatile. 


\subsection{Strategy for Uninformed Traders}

Now we consider the trading strategy of uninformed investors. Hold the strategies and equilibrium for informed traders still. We consider the circumstance that they have a large liquidity demand $S_{2}$ in the beginning. For uninformed traders, they can separate their demand equally into two periods, or satisfy their demand at period 1.

Suppose the liquidity loss for uninformed traders when trade halted is $C^{\prime}<0$. The uninformed investors need to minimize the transaction cost, that is, to determine the minimum number between $S_{2}\left(V^{*}-V\left(S_{2}\right)\right)$ and $S_{1}\left(V^{*}-V\left(S_{1}\right)\right)+S_{1}\left(V\left(S_{1}\right)-V\left(S_{1}, S_{1}\right)\right)$ if the market still survives in period 2, otherwise, uninformed traders will take liquidity loss into his function. We can derive the strategy of uninformed traders in the benchmark case as Proposition 3.

\section{Proposition 3:}

In the benchmark case, uninformed investors tend to separate their orders into two periods no matter the equilibrium is separating equilibrium or pooling equilibrium.

Proof: see appendix.

As for uninformed investors, achieving their liquidity need in the first period will bring them more cost, because the stock price will suffer severe drop if they set large orders. However, if uninformed investors tend to separate their liquidity needs equally into two periods, stock price will drop mildly in both periods, making the liquidity cost lower. Based on the price changes, uninformed investors also tend to split their orders into multiple periods.

Under the separating equilibrium case, we can derive the strategies of uninformed investors as proposition 4 under circuit breakers and price limits.

\section{Proposition 4:}

Under separating equilibrium, when we introduce market-wide circuit breakers or price limits into the market:

1) If $\Delta\left(S_{2}\right)<C$, market will never trigger any circuit breakers and uninformed investors tend to split their orders into two periods.

2) If $\Delta\left(S_{1}\right)>C$, market will trigger both circuit breakers, uninformed investors tend to concentrate their orders if and only if $S_{1}\left(V^{*}-V\left(S_{1}\right)\right)+C^{\prime} \geq S_{2}\left(V^{*}-V\left(S_{2}\right)\right)$ under circuit breakers, and if $S_{1}\left(V^{*}-V\left(S_{1}\right)\right)+\gamma S_{1}\left(V\left(S_{1}\right)-V\left(S_{1}, S_{1}\right)\right)+(1-\gamma) C^{\prime} \geq S_{2}\left(V^{*}-V\left(S_{2}\right)\right)$ under price limits.

3) If $\Delta\left(S_{1}\right) \geq C \geq \Delta\left(S_{2}\right)$, uninformed investors tend to concentrate their orders in periods if and only if $S_{1}\left(V^{*}-V\left(S_{1}\right)\right)+C^{\prime} \geq S_{2}\left(V^{*}-V\left(S_{2}\right)\right)$ under market-wide circuit breakers, and $S_{1}\left(V^{*}-V\left(S_{1}\right)\right)+\gamma S_{1}\left(v\left(S_{1}\right)-V\left(S_{1}, S_{1}\right)\right)+(1-\gamma) C^{\prime} \geq S_{2}\left(V^{*}-V\left(S_{2}\right)\right)$ under price limit rules.

\section{Proof: see Appendix.}

In our consideration, we should not only compare the liquidity cost between splitting orders and concentrating orders, but also we need to take the liquidity 
loss of transaction not completion into account. This liquidity loss may make these uninformed investors set for large orders ahead of the trigger of circuit breakers. Though trading ahead will bring large cost, but it may be smaller than the liquidity loss of trade incompletion.

According to the analysis above, if uninformed investors believe that the market will not stop in the second period, they will split their orders. However, if the uncertainty of trading suspension exists, they will take the liquidity loss into consideration. Moreover, if

$$
\begin{aligned}
& \frac{S_{2}\left(V^{*}-V\left(S_{2}\right)\right)-S_{1}\left(V^{*}-V\left(S_{1}\right)\right)-\gamma S_{1}\left(v\left(S_{1}\right)-V\left(S_{1}, S_{1}\right)\right)}{1-\gamma} \\
& \geq C^{\prime} \geq S_{2}\left(V^{*}-V\left(S_{2}\right)\right)-S_{1}\left(V^{*}-V\left(S_{1}\right)\right)
\end{aligned}
$$

Uninformed investors tend to concentrate their liquidity needs into period 1 under circuit breakers, no matter the market will stop or not in the second period. But they will split their orders equally into two periods under price limits, because the liquidity loss of transaction incompletion is less than the liquidity cost of concentrating orders.

Unlike the behavior of informed investors, uninformed investors tend to be more aggressive under market-wide circuit breakers. They are more likely rush out of the market to avoid the stop of trading. This strategy change will bring more large orders into the market, but these orders are less informative. However, because uninformed investors run out of the market, and informed investors become more conservative, the price of stocks tend to drop further, and eventually triggers the predetermined threshold of circuit breakers, causing the "magnet effect".

\section{Conclusions}

Market-wide circuit breakers and price limits are two similar types of mechanisms imposed in the financial market to protect the market from severe loss. Previous studies discussed the effectiveness of the two circuit breakers, but few of study distinguish between the two mechanisms. We develop a two-period model based on Heish (2007) [10] to study the behavior of institutional and individual investors under different mechanisms. In our paper, we find that informed investors will become more conservative and trade in smaller sizes when we introduce circuit breakers into the market, and this change is more significant under market-wide circuit breakers. Contrary to the behavior of informed investors, uninformed investors tend to realize their liquidity needs earlier under circuit breakers, especially market-wide circuit breakers. To the best of my knowledge, it is the first paper distinguishing the mechanism difference between price limits and circuit breakers theoretically.

Our findings are consistent with Subrahmanyam (1994) [4] and Subrahmanyam (1997) [9]. Because of the behavioral change of different investors, smaller orders tend to contain more information under market-wide circuit breakers, as 
they are supposed to set by institutional investors. There will be more large orders in the market as well, but they are supposed to set by individual investors, based on their sentiment and fear of illiquidity. Under this circumstance, there will be less information released into the market, and the price may be dominated by investors' sentiment or irrational behavior.

Our paper also helps explain the severe market crash in early January, 2016 in Chinese stock market. Because market-wide circuit breakers affect the entire market, it may arouse fear among investors, making them rush out from the market, and cause the severe drop of price. Moreover, because of the conservatism of informed investors, price is more difficult to recover to its underlined value. This phenomenon is more significant when price is approaching the threshold of circuit breakers, causing the "magnet effect".

Moreover, our paper enlightens some political suggestions for the future stock market. When we introduce some new market microstructure mechanism into the Chinese stock market, we need to consider the characteristics of the market. Chinese stock market has a large fraction of retail individual investors, making the market more volatile and easily affected by market sentiment. These characteristics will affect the effectiveness of new policies, which we should consider in advance.

There are also some deficiencies of our paper. The Stackelberg game only contains two periods, making some differences between actual market transactions. Also, we set the informed investors with full information, and uninformed investors with no information at all. These settings are extreme cases. In future studies, we can add more assumptions, and introduce new models for investors' heterogeneity, to better simulate the actual stock market.

\section{Conflicts of Interest}

The author declares no conflicts of interest regarding the publication of this paper.

\section{References}

[1] Lee, C.M.C., Ready, M.J. and Seguin, P.J. (1994) Volume, Volatility, and New York Stock Exchange Trading Halts. The Journal of Finance, 49, 183-214. https://doi.org/10.1111/j.1540-6261.1994.tb04425.x

[2] King, R.G., Plosser, C.I., Stock, J.H., et al. 1987 () Stochastic Trends and Economic Fluctuations. National Bureau of Economic Research. https://doi.org/10.3386/w2229

[3] Kryzanowski, L. (1979) The Efficacy of Trading Suspensions: A Regulatory Action Designed to Prevent the Exploitation of Monopoly Information. The Journal of Finance, 34, 1187-1200. https://doi.org/10.1111/j.1540-6261.1979.tb00064.x

[4] Subrahmanyam, A. (1994) Circuit Breakers and Market Volatility: A Theoretical Perspective. The Journal of Finance, 49, 237-254. https://doi.org/10.1111/j.1540-6261.1994.tb04427.x

[5] Ackert, L.F., Church, B. and Jayaraman, N. (2001) An Experimental Study of Circuit 
Breakers: The Effects of Mandated Market Closures and Temporary Halts on Market Behavior. Journal of Financial Markets, 4, 185-208.

https://doi.org/10.1016/S1386-4181(00)00020-3

[6] Fama, E.F. 1988 () Perspectives on October 1987, or, What Did We Learn from the Crash? Center for Research in Security Prices, Graduate School of Business, University of Chicago.

[7] Kim, K.A. and Rhee, S.G. (1997) Price Limit Performance: Evidence from the Tokyo Stock Exchange. The Journal of Finance, 52, 885-901.

https://doi.org/10.1111/j.1540-6261.1997.tb04827.x

[8] Chen, G.M., Rui, O.M. and Wang, S.S. (2005) The Effectiveness of Price Limits and Stock Characteristics: Evidence from the Shanghai and Shenzhen Stock Exchanges. Review of Quantitative Finance \& Accounting, 25, 159-182.

https://doi.org/10.1007/s11156-005-4247-7

[9] Subrahmanyam, A. (1997) The Ex Ante Effects of Trade Halting Rules on Informed Trading Strategies and Market Liquidity. Review of Financial Economics, 6, 1-14. https://doi.org/10.1016/S1058-3300(97)90011-2

[10] Shufan, H.B. (2007) The Effects of Price Limits on Informed Trading Strategies and Market Performances. Finance.

[11] Brunnermeier, M.K. (2009) Deciphering the Liquidity and Credit Crunch 2007-2008. Journal of Economic Perspectives, 23, 77-100.

https://doi.org/10.1257/jep.23.1.77

[12] Easley, D. and O'hara, M. (1987) Price, Trade Size, and Information in Securities Markets. Journal of Financial Economics, 19, 69-90.

https://doi.org/10.1016/0304-405X(87)90029-8 


\section{Appendix A. Proof of Propositions}

\section{Proposition 1:}

Under separating equilibrium, informed investors tend to declare a large order size if they possess information, after receiving large order, the probability $\delta(S)$ and stock price $V(S)$ will turns into

$$
\begin{gathered}
\delta\left(S_{2}\right)=\frac{\delta\left(\alpha \mu+(1-\alpha \mu) X_{2}\right)}{\alpha \mu \delta+(1-\alpha \mu) X_{2}} \\
V\left(S_{2}\right)=\delta\left(S_{2}\right) \underline{V}+\left(1-\delta\left(S_{2}\right)\right) \bar{V}=V^{*}-\frac{\delta(1-\delta) \alpha \mu}{\alpha \mu \delta+(1-\alpha \mu) X_{2}}(\bar{V}-\underline{V})
\end{gathered}
$$

In order to ensure the separating equilibrium, we need

$$
\begin{gathered}
\Pi_{2}\left(S_{2}, S_{2}\right) \geq \Pi_{2}\left(S_{2}, S_{1}\right) \\
\Pi_{1}\left(S_{2}\right)+\Pi_{2}\left(S_{2}, S_{2}\right) \geq \Pi_{1}\left(S_{1}\right)+\Pi_{2}\left(S_{1}, S_{2}\right)
\end{gathered}
$$

By deriving the two conditions, we have

$$
\begin{gathered}
\frac{S_{2}}{S_{1}} \geq \frac{1-\delta\left(S_{2}, S_{1}\right)}{1-\delta\left(S_{2}, S_{2}\right)}=\frac{X_{1}\left[X_{2}(1-\mu \alpha)+\delta\left(S_{2}\right) \alpha \mu\right]}{X_{2}\left[X_{1}(1-\mu \alpha)+\delta\left(S_{2}\right) \alpha \mu\right]} \\
\frac{S_{2}}{S_{1}} \geq \frac{1-\delta\left(S_{1}\right)}{1-\delta\left(S_{2}\right)+\delta\left(S_{1}, S_{2}\right)-\delta\left(S_{2}, S_{2}\right)}
\end{gathered}
$$

As condition (A.6) contains (A.5), we only need to ensure (A.6) stands. This is condition (1) in proposition.

Under separating equilibrium, the order size does not affect the profit of informed investors. Suppose $\varphi$ is the probability of declaring small orders after receiving information. In this case, the probability $\delta$ can be derived as

$$
\begin{gathered}
\delta\left(S_{1}, \varphi\right)=\frac{\delta\left(\alpha \mu \varphi+(1-\alpha \mu) X_{1}\right)}{\alpha \mu \delta \varphi+(1-\alpha \mu) X_{1}} \\
\delta\left(S_{2}, \varphi\right)=\frac{\delta\left(\alpha \mu(1-\varphi)+(1-\alpha \mu) X_{2}\right)}{\alpha \mu \delta(1-\varphi)+(1-\alpha \mu) X_{2}}
\end{gathered}
$$

And we have

$$
S_{2}\left(1-\delta\left(S_{2}, \varphi\right)\right)=S_{1}\left(1-\delta\left(S_{1}, \varphi\right)\right)
$$

For some $\varphi$ between 0 and 1. As $\delta\left(S_{1}, \varphi\right)$ increases with $\varphi$, and $\delta\left(S_{2}, \varphi\right)$ decreases with $\varphi$. Then we need to have

$$
\begin{aligned}
& S_{2} \cdot\left(V\left(S_{i}, S_{2}, \varphi\right)-\underline{V}\right) \geq S_{1} \cdot\left(V\left(S_{i}, S_{1}, \varphi\right)-\bar{V}\right) \\
& S_{1} \cdot\left(V\left(S_{1}, \varphi\right)-\underline{V}\right)+S_{2} \cdot\left(V\left(S_{1}, S_{2}, \varphi\right)-\underline{V}\right) \\
& =S_{2} \cdot\left(V\left(S_{2}, \varphi\right)-\underline{V}\right)+S_{2} \cdot\left(V\left(S_{2}, S_{2}, \varphi\right)-\underline{V}\right)
\end{aligned}
$$

i.e.

$$
\frac{1-\delta}{1-\delta\left(S_{2}, S_{2}\right)} \leq \frac{S_{2}}{S_{1}} \leq \frac{1-\delta\left(S_{1}\right)}{1-\delta\left(S_{2}\right)+\delta\left(S_{1}, S_{2}\right)-\delta}
$$


This is condition (2) in proposition.

Proposition 2:

Under separating equilibrium, we have

$$
\frac{S_{2}}{S_{1}} \geq \frac{1-\delta\left(S_{1}\right)}{1-\delta\left(S_{2}\right)+\delta\left(S_{1}, S_{2}\right)-\delta\left(S_{2}, S_{2}\right)}
$$

Under market-wide circuit breakers, if we want informed investors ask for a large order in period 1 , we need to have

$$
S_{2}\left(V\left(S_{2}\right)-\underline{V}\right) \geq S_{1}\left(V\left(S_{1}\right)-\underline{V}\right)+S_{2}\left(V\left(S_{1}, S_{2}\right)-\underline{V}\right)
$$

Deriving the above formula, we have

$$
\frac{S_{2}}{S_{1}} \geq \frac{1-\delta\left(S_{1}\right)}{\delta\left(S_{1}, S_{2}\right)-\delta\left(S_{2}\right)}
$$

Also, under price limits, if we want informed investors ask for large orders in period 1 , we need to have

$$
\begin{aligned}
& S_{2}\left(V\left(S_{2}\right)-\underline{V}\right)+\gamma S_{2}\left(V\left(S_{2}, S_{2}\right)-\underline{V}\right) \\
& \geq S_{1}\left(V\left(S_{1}\right)-\underline{V}\right)+S_{2}\left(V\left(S_{1}, S_{2}\right)-\underline{V}\right)
\end{aligned}
$$

i.e.

$$
\frac{S_{2}}{S_{1}} \geq \frac{1-\delta\left(S_{1}\right)}{\delta\left(S_{1}, S_{2}\right)-\delta\left(S_{2}\right)+\gamma\left(1-\delta\left(S_{2}, S_{2}\right)\right)}
$$

Proposition3:

For uninformed investors, in order to prove they will separate their orders, we need to prove

$$
S_{2}\left(V^{*}-V\left(S_{2}\right)\right) \geq S_{1}\left(V^{*}-V\left(S_{1}\right)\right)+S_{1}\left(V\left(S_{1}\right)-V\left(S_{1}, S_{1}\right)\right)
$$

i.e.

$$
2\left(V^{*}-V\left(S_{2}\right)\right) \geq V^{*}-V\left(S_{1}, S_{1}\right)
$$

By deriving the price $V(S)$ and $V\left(S, S^{\prime}\right)$, we only need to prove

$$
\begin{gathered}
2\left(\delta\left(S_{2}, \varphi\right)-\delta\right)>\delta\left(S_{1}, S_{1}, \varphi\right)-\delta \\
2\left(\delta\left(S_{2}\right)-\delta\right)>\delta\left(S_{1}, S_{1}\right)-\delta
\end{gathered}
$$

We have

$$
\begin{aligned}
\delta\left(S_{1}, S_{1}\right) & =\frac{\delta\left(S_{1}\right) \cdot\left(\alpha \mu+(1-\alpha \mu) X_{1}\right)}{\delta\left(S_{1}\right) \cdot \alpha \mu+(1-\alpha \mu) X_{1}} \\
& =\delta\left(S_{1}\right)+\frac{\alpha \mu \cdot \delta\left(S_{1}\right) \cdot\left(1-\delta\left(S_{1}\right)\right)}{\delta\left(S_{1}\right) \cdot \alpha \mu+(1-\alpha \mu) X_{1}} \\
\delta\left(S_{1}, S_{1}, \varphi\right) & =\frac{\delta\left(S_{1}, \varphi\right) \cdot\left(\alpha \mu+(1-\alpha \mu) X_{1}\right)}{\delta\left(S_{1}, \varphi\right) \cdot \alpha \mu+(1-\alpha \mu) X_{1}} \\
& =\delta\left(S_{1}, \varphi\right)+\frac{\alpha \mu \cdot \delta\left(S_{1}, \varphi\right) \cdot\left(1-\delta\left(S_{1}, \varphi\right)\right)}{\delta\left(S_{1}, \varphi\right) \cdot \alpha \mu+(1-\alpha \mu) X_{1}}
\end{aligned}
$$


Define

$$
\begin{gathered}
F\left(\delta\left(S_{1}\right)\right)=\delta\left(S_{1}, S_{1}\right)-\delta\left(S_{1}\right)=\frac{\alpha \mu \cdot \delta\left(S_{1}\right) \cdot\left(1-\delta\left(S_{1}\right)\right)}{\delta\left(S_{1}\right) \cdot \alpha \mu+(1-\alpha \mu) X_{1}} \\
F\left(\delta\left(S_{1}, \varphi\right)\right)=\delta\left(S_{1}, S_{1}, \varphi\right)-\delta\left(S_{1}, \varphi\right)=\frac{\alpha \mu \cdot \delta\left(S_{1}, \varphi\right) \cdot\left(1-\delta\left(S_{1}, \varphi\right)\right)}{\delta\left(S_{1}, \varphi\right) \cdot \alpha \mu+(1-\alpha \mu) X_{1}}
\end{gathered}
$$

We have

$\frac{\partial F\left(\delta\left(S_{1}\right)\right)}{\partial \delta\left(S_{1}\right)}=\frac{\alpha \mu\left(1-2 \delta\left(S_{1}\right)\right)\left[\delta\left(S_{1}\right) \cdot \alpha \mu+(1-\alpha \mu) X_{1}\right]-\alpha^{2} \mu^{2} \cdot \delta\left(S_{1}\right) \cdot\left(1-\delta\left(S_{1}\right)\right)}{\left[\delta\left(S_{1}\right) \cdot \alpha \mu+(1-\alpha \mu) X_{1}\right]^{2}}$

As

$$
\delta\left(S_{1}\right)>\delta \geq \frac{1}{2}
$$

We have

$$
\frac{\partial F\left(\delta\left(S_{1}\right)\right)}{\partial \delta\left(S_{1}\right)}<0
$$

i.e.

$$
F\left(\delta\left(S_{1}\right)\right)<F(\delta)=\delta\left(S_{1}\right)-\delta
$$

Then we can derive (A.20) and (A.21).

Proposition 4:

We need to compare $S_{2}\left(V^{*}-V\left(S_{2}\right)\right)$ and

$S_{1}\left(V^{*}-V\left(S_{1}\right)\right)+S_{1}\left(V\left(S_{1}\right)-V\left(S_{1}, S_{1}\right)\right)$. The calculation is similar to proposition 2 . 